\title{
EDITORIAL
}

\section{Severe intraventricular hemorrhage in a new decade: what do we tell parents?}

\author{
Journal of Perinatology (2014) 34, 167-168; \\ doi:10.1038/jp.2013.165
}

As neonatologists, we are continually faced with the task of prognosticating outcomes for the families of our patients. From the moment we walk into the labor room of a woman about to deliver a 24-week infant to that very child's final follow-up clinic visit, we are asked for our best estimate of what we think are 'the odds' of survival, of going home by the holidays, of being able to walk someday and of simply having a 'normal life.' For many neonatal intensive care unit (NICU) clinicians, one of the most distressing discussions to anticipate is the disclosure to a family that their infant has a 'severe' intraventricular hemorrhage (IVH) on cranial ultrasound. Historically, severe IVH has been classified as a Grade 3 or 4 IVH according to Papile and has been associated with higher rates of neurodevelopmental impairment (NDI) compared to Grades 1 and $2 \mathrm{IVH}^{1-3}$ These sequelae have included cerebral palsy, cognitive delays and neurosensory deficits. ${ }^{4-8}$ Although Grade $4 \mathrm{IVH}$ is now understood to represent periventricular hemorrhagic infarction (PVHI) rather than true extension of hemorrhage, it continues to be classified according to Papile and most often is combined with Grade 3 IVH as a composite measure despite the differences in pathophysiology and outcome. Even among infants with PVHI, the spectrum of ventricular and parenchymal involvement is so expansive that it is impossible to use a universal approach to prognostication, and many would question whether we should make prophecies based on a radiologic study. Neurodevelopmental outcome studies done shortly after the advent of cranial ultrasound imaging had hoped that prompt identification of infants with 'irreversible brain damage' might reassure clinicians that withdrawal of medical support was both ethical and compassionate on the basis of an impending future so bleak. ${ }^{8}$ Literature on the sequelae of severe IVH continues to be limited by the fact that large numbers of children do not survive due to redirection of care in the NICU, and often on the basis of their IVH. As such, there is a necessity to understand the outcome of children who live with these diagnoses that is paramount.

Fortunately, with advances in perinatal management, including high utilization of antenatal steroids, the rates of Grades 3 and 4 IVH have diminished in the past two decades. ${ }^{9-12}$ Rates of severe IVH for very low birth weight (VLBW) infants in the Vermont Oxford Network declined from $10 \%$ to $6 \%$ from 1991-2009.9,10 Similarly, severe IVH rates for extremely low birth weigh infants in the National Institute of Child Health and Human Development (NICHD) Neonatal Research Network (NRN) born in 1995-1996 were $38 \%$ but for extremely preterm (EPT) infants born in 20032007 were only $16 \%$ with the majority of cases occurring in infants of 22-23 weeks' gestation. ${ }^{11,12}$ Consequently, a major limitation of contemporary studies on severe IVH is small cohort size. There is also immense heterogeneity both within and between studies in terms of neonatal and socio-demographic traits of the population, differences in neuroimaging protocols and timing and rates of neonatal follow-up that complicate efforts to consolidate findings. Finally, it must be acknowledged that neurodevelopmental outcomes of VLBW infants born in the second half of the 1990s are confounded by high rates of postnatal steroid exposure, which has been shown to have its own adverse effect on neurologic outcome in survivors of IVH. ${ }^{13}$

In this issue of the Journal of Perinatology, Dr Davis and colleagues from the NICHD NRN present the largest analysis to date of early childhood neurodevelopmental outcome of infants with a diagnosis of Grade 3 or $4 \mathrm{IVH} .{ }^{14}$ It is the only study to specifically evaluate the impact of this morbidity in infants of $\leqslant 26$ weeks' gestational age as well for infants born since 2006. The high rate of antenatal steroid (78\%) and low rate of postnatal steroid exposure $(20 \%)$ underscore the changes in practice that have occurred since publication of prior studies. The authors wished to better delineate the qualities of severe IVH that impact neurodevelopmental outcome, specifically laterality (unilateral vs bilateral) and the absence or presence of parenchymal involvement in IVH while adjusting for other clinical variables through both logistic regression and classification and regression tree (CART) analysis. Unadjusted rates of moderate to severe cerebral palsy were $16 \%$ for the entire cohort but were significantly lower for those with unilateral vs bilateral IVH ( 8 vs $21 \%$ ) and for those without parenchymal involvement (10 vs $24 \%$ ). Furthermore, $47 \%$ of this high-risk cohort was unimpaired at 18-22 month follow-up. Regression analyses revealed that bilateral IVH and PVHI alongside birthweight, namely when $\leqslant 707 \mathrm{~g}$ as computed through the CART program, were the most significant predictors of the combined outcome of death/NDI. However, when analyses were limited to survivors the most significant predictors of adverse outcome through both methods of analysis were need for a shunt and exposure to postnatal steroids, with severe IVH exerting a lesser effect.

These findings although markedly improved from the early reports on neurodevelopmental sequelae of severe IVH, are consistent with recent data on premature infants born in 1995$2005 .^{13,15-17}$ In a large study of 214 infants with severe IVH, only $7.4 \%$ of those with Grade 3 and $49 \%$ with Grade 4 IVH had cerebral palsy and the majority had normal developmental quotients at 24 months. ${ }^{15}$ Others have also attempted to elucidate features of IVH and/or comorbid conditions which negatively impact prognosis. In a multicenter analysis of 69 VLBW infants with PVHI, rates of moderate to severe cerebral palsy were $37 \mathrm{vs} 88 \%$ and for $\mathrm{MDI}<70$ were 36 vs $93 \%$ for infants with unilateral vs bilateral involvement, respectively at $18-36$ months. ${ }^{16}$ Furthermore, for infants with unilateral PVHI who did not have concomitant periventricular leukomalacia and/or severe retinopathy of prematurity the rate of $\mathrm{MDI}<70$ was only $24 \% .{ }^{16}$ Merhar et al. ${ }^{13}$ evaluated the impact of laterality on all grades of IVH in 166 extremely low birth weigh infants and founds that infants with Grade $3 \mathrm{IVH}$, even when bilateral, had outcomes which were comparable to those of infants with Grades 1-2 IVH.

Perhaps one of the most informative and sobering numbers in this study is the mortality rate of $55 \%$ that is much higher than in other recent reports of infants with severe $\mathrm{IVH}^{15,17}$ However, when one considers that the mean gestational age of the study cohort was $24 \pm 1$ weeks, it begs the question of how much medical decision-making is done on the basis of gestational age vs the presence of severe IVH? Recent reports from the NRN 
demonstrated similar mortality rates for infants at the threshold of viability and confirmed the fact that the majority of infants who died had withdrawal of life-sustaining measures. ${ }^{12}$ In this study, half of all redirection of care was due to $\mathrm{IVH}$, something which the authors acknowledge as a limitation and address in separate analyses. Composite outcomes of death/NDI are problematic to interpret in situations involving a high rate of withdrawal of support because it can rarely be determined retrospectively if death would have been inevitable or was solely due to the redirection of care. Furthermore, to a family of an EPT infant with severe $\mathrm{IVH}$, the only relevant outcome is that of an infant who does survive to go home and for that family the question will always be about the odds of 'having a normal life.' Davis et al. ${ }^{14}$ have shown that at least in early childhood almost half of these children will be normal, a number which will surprise many clinicians and be of great comfort and hope to a family.

Undoubtedly, prognostication in the NICU is a complex process. As the overwhelming majority of severe IVH now occurs in infants born at the threshold of viability, clinicians will need to disentangle the competing influence of gestational age, neonatal morbidities and well-intentioned therapies on neurodevelopmental outcome. Early identification of infants who require a shunt as well as continued judicious use of postnatal steroids may be more beneficial than any blanket statement on adverse outcomes of severe IVH, particularly for this population. Finally, discussions with a family of an infant with severe IVH on how to direct medical care should always take into account the global picture, that these brain injuries will increase the risk of NDI, but also never lose sight of the mounting evidence that large numbers of infants survive into early childhood without impairment.

\section{CONFLICT OF INTEREST}

The author declares no conflict of interest.

\section{K Patra \\ Department of Pediatrics, Rush University Medical Center, Chicago, IL, USA E-mail: kousiki_patra@yahoo.com}

\section{REFERENCES}

1 Papile LA, Burstein J, Burstein R, Koffler $\mathrm{H}$. Incidence and evolution of subependymal and intraventricular hemorrhage: a study of infants with birth weights less than $1500 \mathrm{gm}$. J Pediatr 1978; 92(4): 529-534.

2 Krishnamoorthy KS, Shannon DC, DeLong GR, Todres ID, Davis KR. Neurologic sequelae in the survivors of neonatal intraventricular hemorrhage. Pediatrics 1979; 64: $233-237$.
3 Papile LA, Munsick-Bruno G, Schaefer A. Relationship of cerebral intraventricular hemorrhage and early childhood neurologic handicaps. J Pediatr 1983; 103(2): 273-277.

4 Hack M, Wilson-Costello D, Friedman H, Taylor GH, Schluchter M, Fanaroff AA. Neurodevelopment and predictors of outcomes of children with birth weights of less than [1000] 1992-1995. Arch Pediatr Adolesc Med 2000; 154(7): 725-731.

5 Futagi $Y$, Toribe $Y$, Ogawa K, Suzuki Y. Neurodevelopmental outcome in children with intraventricular hemorrhage. Pediatr Neurol 2006; 34(3): 219-224.

6 Beaino G, Khoshnood B, Kaminski M, Pierrat V, Marret S, Matis J et al. EPIPAGE Study Group. Predictors of cerebral palsy in very preterm infants: the EPIPAGE prospective population-based cohort study. Dev Med Child Neurol 2010; 52(6): e119-e125.

7 Vohr BR, Wright LL, Poole WK, McDonald SA. for the NICHD Neonatal Research Network Follow-Up Study. Neurodevelopmental outcomes of extremely low birth weight infants <32 weeks' gestation between 1993 and 1998. Pediatrics 2005; 116: 635-643.

8 Catto-Smith AG, Yu VY, Bajuk B, Orgill AA, Astbury J. Effect of neonatal periventricular haemorrhage on neurodevelopmental outcome. Arch Dis Child 1985; 60(1): 8-11.

9 Horbar JD, Badger GJ, Carpenter JH, Fanaroff AA, Kilpatrick S, LaCorte M et al. for the Vermont Oxford Network: trends in mortality and morbidity for very low birth weight infants, 1991-1999. Pediatrics 2002; 110(1): 143-151.

10 Horbar JD, Carpenter JH, Badger GJ, Kenny MJ, Soll RF, Morrow KA et al. for the Vermont Oxford Network: mortality and neonatal morbidity among infants 501 to 1500 grams from 2000-2009. Pediatrics 2012; 129(6): 1019-1026.

11 Lemons JA, Bauer CR, Oh W, Korones SB, Papile L, Stoll BJ et al. Very low birth weight outcomes of the National Institute of Child Health and Human Development Neonatal Research Network, January 1995 through December 1996. Pediatrics 2001; 107(1): E1.

12 Stoll BJ, Hansen NI, Bell EF, Shankaran S, Laptook AR, Walsh MC et al. Eunice Kennedy Shriver National Institute of Child Health and Human Development Neonatal Research Network. Neonatal outcomes of extremely preterm infants from the NICHD Neonatal Research Network. Pediatrics 2010; 126(3): 443-456.

13 Merhar S, Tabangin ME, Meinzen-Derr J, Schibler KR. Grade and laterality of intraventricular haemorrahge to predict 18-22 month neurodevelopmental outcomes in extremely low birthweight infants. Acta Pediatrica 2012; 101: 414-418.

14 Davis AS, Hintz SR, Goldstein RF, Ambalavanan N, Bann CM, Stoll BJ et al. Eunice Kennedy Shriver National Institute of Child Health and Human Development Neonatal Research Network. Outcomes of extremely preterm infants following severe intracranial hemorrhage. J Perinatol. (this issue).

15 Brouwer A, Groenendaal F, van Haastert IL, Rademaker K, Hanlo P, de Vries L. Neurodevelopmental outcome of preterm infants with severe intraventricular hemorrhage and therapy for post-hemorrhagic ventricular dilatation. J Pediatr 2008; 152(5): 648-654.

16 Maitre NL, Marshall DD, Price WA, Slaughter JC, O'Shea TM, Maxfield C et al. Neurodevelopmental outcome of infants with unilateral or bilateral periventricular hemorrhagic infarction. Pediatrics 2009; 124(6): e1153-e1160.

17 Roze E, Van Braeckel KNJA, van der Veere CN, Maathuis CGB, Martijn A, Bos AF. Functional outcomes at school age of preterm infants with periventricular hemorrhagic infarction. Pediatrics 2009; 123(6): 1493-1500. 